\title{
An uncomplicated but difficult two-part learning set task'
}

MYMON GOLDSTEIM, LONG ISLAND UNIVERSITY

PETER D. WRIGHT, WESTMINSTER CHOIR COLLEGE

A two-part learning set design was obtained by relating a positional discrimination in Part 1 to a new vs. old object discrimination in Part 2. Only 11.1\% of 162 human Ss mastered the relationship between Part 1 and Part 2 .

The Harlow (1949) learning set paradigm was recently generalized by Goldstein \& Weber (1966), who achieved a task of moderate difficulty for humans. The essence of the Goldstein \& Weber (1966) procedure was a two-part problem design in which the events of Part 1 governed assignment of reinforcement during Part 2. A further development of two-part learning set methodology is afforded by the present study, which involves a task simpler in design than that of Goldstein \& Weber (1966), yet apparently more difficult for humans.

Method

The study involved 80 problems with identical formats but different stimuli (see Fig. 1). Ss sequenced from Problem 1, Part 1 to Problem 1, Part 2 to Problem 2, Part 1, etc. to Problem 80, Part 2. In each problem, Part 1 was a discrimination of the type $x$ vs, $x$, whose correct alternative was either on the left or on the right; Part 2 was a discrimination of the type $x$ vs. $y$, in which position was irrelevant and the correct alternative was either $x$, the "old" stimulus that had appeared previously in Part 1, or else $y$, the "new" stimulus. The reinforcement patterns of Part 1 and Part 2 were related as follows: if left was correct on the $x$ vs. $x$ displays in Part 1 , then $x$, the old stimulus, was correct on the $x$ vs. $y$ displays in Part 2; if right was correct in Part 1, then $y$, the new stimulus, was correct in Part 2 . Ss who mastered the relationship between the two parts could achieve errorless performance in Part 2, but those who missed the relationship had to tackle Part 2, like Part 1, with an opening guess. Designations of Part 1: left-Part 2: old and Part 1: right-Part 2: new as the correct alternatives were counterbalanced over problems.

A two-treatment variable and a three-treatment variable were combined to produce a six-group experiment. There were 27 Ss per group. The two-treatment variable dealt with number of trials: each part of each problem had either one trial or two trials, as indicated in Fig. 1. The one-trial arrangement was obtained by deleting second trials after the two-trial arrangement had been constructed. The three-treatment variable dealt with chronological age, and compared the performance of fifth, eighth and eleventh graders. ${ }^{2}$

Printed booklets served as the method of task administration. The booklets were arranged to provide a complete trial on each sheet: there were two stimuli as in Fig. 1 plus two opaque squares of ink, one below each stimulus. To choose a stimulus, $S$ erased the square immediately below it, and the erasure revealed a previously hidden check if the choice was correct, but blank paper if the choice was incorrect. S was instructed to respond only once per sheet and to sequence con-

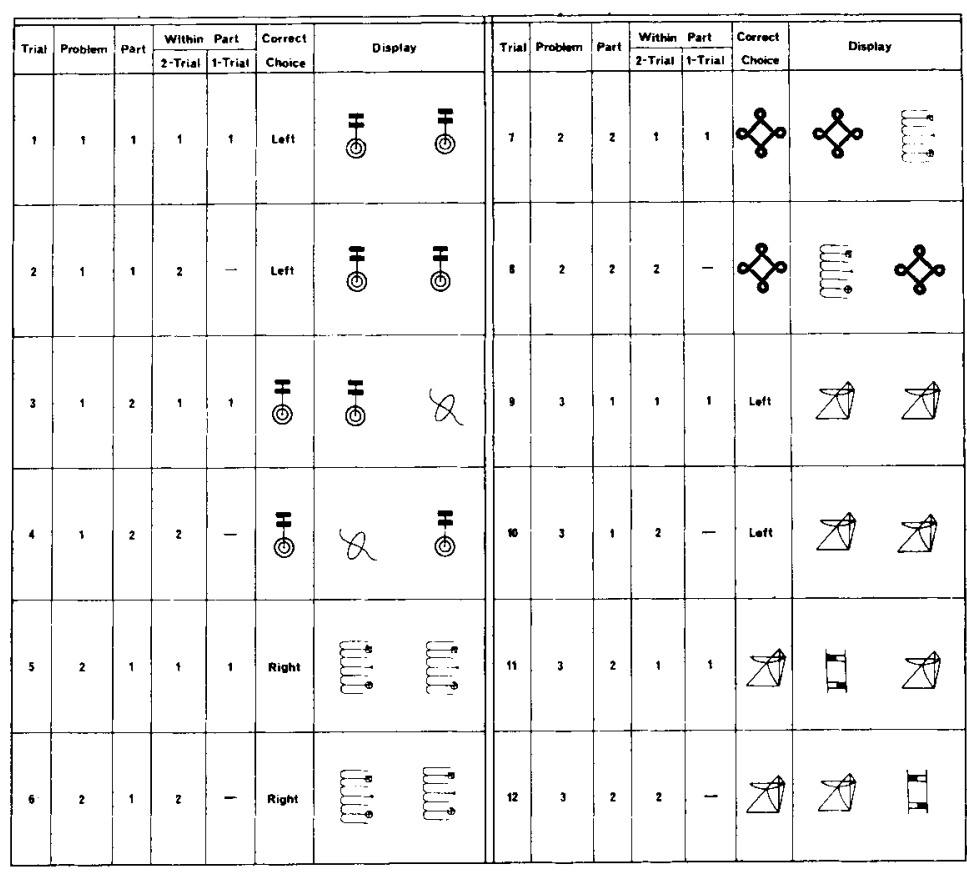

Fig. 1. Design of the experiment. Trial numbers at the left correspond to the 2-trial treatment, from which the 1-trial treatment was obtained by omission of altemate displays. There were 80 problems in all. 


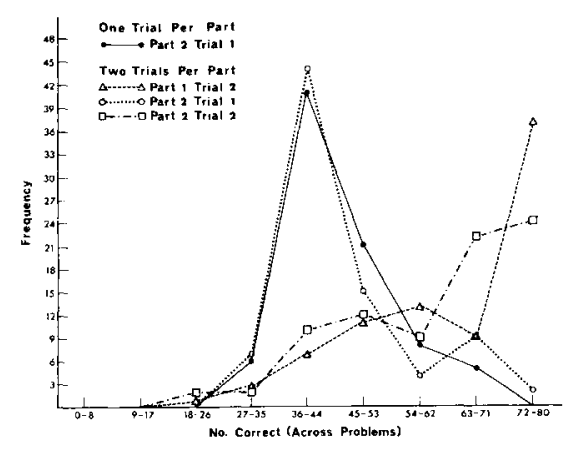

Fig. 2. Frequency functions for number of correct responses per trial tallied across problems. Grade levels are combined.

tinuously through the booklet without looking back. A group method of administration was employed, and all Ss in a given grade served simultaneously. There was no time limit.

\section{Results and Discussion}

Means and standard deviations are reported in Table 1 for number of correct responses per trial summed over problems. Trial 1 of Part 1 is omitted because it required a guess, but Trial 1 of Part 2 is included because it could be mastered if the relationship between Part 1 and Part 2 was grasped by $\mathrm{S}$. The evidence for all six groups in Table 1 indicates that most Ss did not grasp the Part 1-Part 2 relationship, and that response to Trial 1 of Part 2 was little different from the guessing level of 40 that would be expected if Part 1 were not related to Part 2 at all.

The other trials represented in Table 1 could be mastered with or without attendant mastery of the Part 1-Part 2 relationship, because each of them repeated the alternatives and the reinforcement designation of the preceding trial, in the standard manner of learning set. The means for these trials were substantially larger than 40. A two-way analysis of variance involving the data for the groups with two trials per part yielded a significant trials effect $(p<.001)$ but an insignificant grade level effect. The grade level effect was significant at the .05 level in a one-way analysis of variance involving the data for the groups with one trial per part, but the numerical differences were neither large nor monotonic and seem best disregarded.

Another useful way of looking at the results is provided by Fig. 2, which contains frequency functions. Each function plotted represents an $\mathrm{N}$ of 81 obtained

Table 1. Correct Responses Summed Across Problems for Designated Trials $(\mathbf{N}=27)$

\begin{tabular}{|c|c|c|c|c|c|c|c|}
\hline \multicolumn{2}{|c|}{ No. of Trials } & \multicolumn{2}{|c|}{ Part 1, Trial 2} & \multicolumn{2}{|c|}{ Part 2, Trial 1} & \multicolumn{2}{|c|}{ Part 2, Trial 2} \\
\hline per & Grade & $M$ & SD & $M$ & SD & $M$ & SD \\
\hline \multirow[t]{3}{*}{1} & 5 & -- & -- & 45.2 & 6.2 & - & -- \\
\hline & 8 & -- & $-\infty$ & 42.1 & 5.5 & -- & -- \\
\hline & 11 & -- & -- & 48.4 & 11.7 & -- & -- \\
\hline \multirow[t]{3}{*}{2} & 5 & 62.6 & 12.6 & 44.9 & 8.8 & 55.0 & 15.7 \\
\hline & 8 & 62.8 & 15.0 & 46.3 & 10.8 & 63.1 & 15.5 \\
\hline & 11 & 64.7 & 15.0 & 45.4 & 12.5 & 63.3 & 12.0 \\
\hline
\end{tabular}

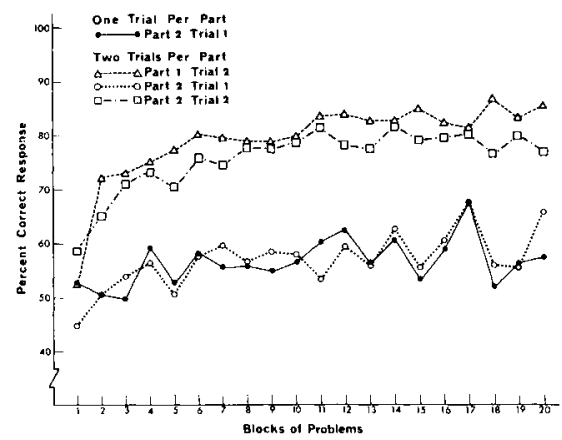

Fig. 3. Learning curves as a function of problems, with trials distinguished. Grade levels are combined and problems are plotted in blocks of four.

by combining the three grade levels. The two curves for Part 2, Trial 1 are nearly binomial, but not quite. The region from 54 to 80 possesses a few cases more than can be explained by a random binomial mechanism. Apparently, a handful of Ss did learn something about the relationship between Part 1 and Part 2 .

The curves for Part 1, Trial 2 and Part 2, Trial 2 show only a minor effect attributable to a binomial mechanism at the left of the abscissa. The most prominent effect is a preponderance of Ss who showed clear evidence of learning, as indicated by large frequencies for the values at the far right of the abscissa.

The main features of Fig. 2 were also exhibited by criterion data representing the percentage of Ss who terminated performance with a run of 10 or more consecutive correct responses tallied across problems for a designated trial. The Part 2, Trial 1 percentages were $8.6 \%$ for all Ss with one trial per part (combined across grade levels) and $13.6 \%$ for all Ss with two trials per part (also combined across grade levels). The corresponding percentages for Part 1, Trial 2 and Part 2, Trial 2 were $53.1 \%$ and $38.3 \%$, respectively.

Learning curves are plotted in Fig. 3 , whose points represent combined data for all grade levels on a block of four successive problems, i.e., there are 324 observations per point. The two curves for Part 2, Trial 1 show little, if any trend because few Ss mastered this aspect of the task. The curves for Part 1, Trial 2 and Part 2, Trial 2 show that such learning as occurred was dramatic over the first three blocks of problems but then much more gradual.

\section{References}

Goldstein, M., \& Weber, R. J. Symbols via learning set. Percept. mot. Skills, 1966, 22, 351-358.

Harlow, H. F. The formation of learning sets. Psychol. Rev., $1949,56,51-65$.

\section{Notes}

1. This study was supported by the Secondary School Science Project at Princeton University as part of its activities under grants from the National Science Foundation.

2. We wish to acknowledge the cooperation and assistance of Chester R. Stroup, Superintendent of Schools, W. Donald Clark, Director of Special Services, and Kenneth E. Michael, Howard B. Waxwood, and Dorothea W. Lummis, School Principals in the Borough of Princeton, New Jersey. 